\title{
A Conceptual Design Application Based ON A NEW GENERALIZED ALGORITHM
}

\author{
NeAgOe, M.; Diaconescu, D.; Jaliu, C. \& SAUlescu, R.
}

Abstract: Based on a new algorithm variant of the conceptual design modeling, proposed by the authors, an application of this algorithm is analyzed on a product of motor - planetary reducer type. According to the new variant, the paper exemplifies the generation of the reducer solving structural variants and the reducer concept establishment.

Key words: conceptual design, product concept, generalized algorithm, planetary reducer concept
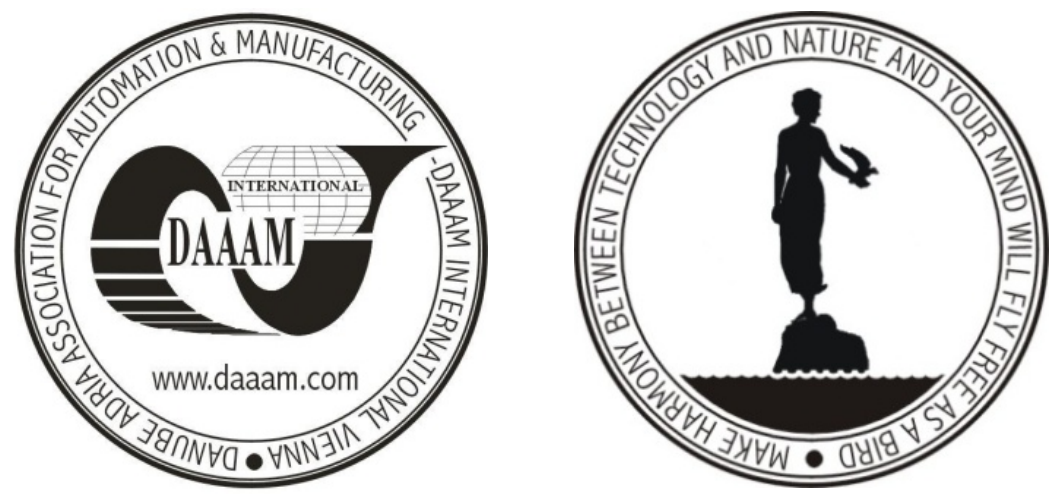

Authors' data: Univ.Prof. Dipl.-Eng. Dr. Neagoe, M[ircea]; Univ.Prof. Dipl.-Eng. Dr. Diaconescu, D[orin]; Univ.Prof. Dipl.-Eng. Dr. Jaliu, C[odruta]; Univ.Lecturer Dipl.-Eng. Dr. Saulescu, R[adu], Transilvania University of Brasov, Eroilor 29, 500036, Brasov, Romania, mneagoe@unitbv.ro, dvdiaconescu@unitbv.ro, cjaliu@unitbv.ro,rsaulescu@unitbv.ro.

This Publication has to be referred as: Neagoe, M[ircea]; Diaconescu, D[orin]; Jaliu, C[odruta] \& Saulescu, R[adu] (2009). A Conceptual Design Application Based on a new Generalized Algorithm, Chapter 63 in DAAAM International Scientific Book 2009, pp. 653-664, B. Katalinic (Ed.), Published by DAAAM International, ISBN 978-3-901509-69-8, ISSN 1726-9687, Vienna, Austria

DOI: $10.2507 /$ daaam.scibook.2009.63 